\title{
The effect of information, education and communication on knowledge and practice regarding prevention/treatment of iron deficiency anaemia among the antenatal women attending primary health centre in Puducherry, India: a randomised control study
}

\author{
Athul Chandran*, Subashini M, Nina Kate
}

Department of Obstetrics and Gynecology, Rajiv Gandhi Government Women and Children Hospital, Puducherry, India

Received: 19 March 2019

Accepted: 04 May 2019

*Correspondence:

Dr. Athul Chandran,

E-mail: athulchandran00@gmail.com

Copyright: () the author(s), publisher and licensee Medip Academy. This is an open-access article distributed under the terms of the Creative Commons Attribution Non-Commercial License, which permits unrestricted non-commercial use, distribution, and reproduction in any medium, provided the original work is properly cited.

\section{ABSTRACT}

Background: IEC (Information, Education, and Communication) strategies may help pregnant women to prevent disease and to improve and maintain health. The present study was carried out with an aim to evaluate the effectiveness of IEC in improving the knowledge and practice regarding prevention/treatment of iron deficiency anaemia among the antenatal women attending Primary Health Centre in Puducherry.

Methods: The present study was carried out in Puducherry, as a randomised control trial among antenatal mothers attending antenatal clinics in Primary Health Centre from February 2016 to August 2017. Block randomization technique was used to designate study participants into intervention and non-intervention groups. The minimum required sample size was calculated to be 84 in each group. Then intervention (Information, Education and Communication) was given to these antenatal women by using interpersonal communication methods, PowerPoint presentation and audio visual aids.

Results: Correct responses to the questions were compared among the intervention and non intervention group in pre test and post test. It was noted that the proportion of correct responses were significantly higher among intervention group than that of non-intervention groups.

Conclusions: Well planned and tailor made IEC material, acceptable by the regional population, by using various modes of interpersonal communication, improves the knowledge and practice of the antenatal mothers. It was also found that the haemoglobin levels of mothers in the intervention group were higher than the antenatal mothers who did not receive any IEC intervention.

Keywords: Anaemia, Antenatal mothers, IEC, Knowledge, Practice

\section{INTRODUCTION}

Anaemia is one of the world's leading causes of disability and hence it is considered as one of the important public health problems. Iron deficiency Anaemia is one of the most prevalent micro nutrient deficiency. ${ }^{1}$ Also, young children, pregnant and postpartum women are the most commonly and severely affected because of the high iron demands during pregnancy and infant growth. Nearly half of all pregnant women in the world i.e., 52\% in developing countries and $23 \%$ in the developed world are anemic, according to an estimate in the beginning of $21^{\text {st }}$ century. ${ }^{2}$ Differences between various parts of the world could be because of differences in socioeconomic conditions, lifestyles and health-seeking behaviours 
across different cultures in the world. It was reported by the WHO that in developing countries, iron deficiency anaemia is aggravated by worm infestation, malaria and other infectious diseases such as HIV and tuberculosis. Also, anaemia contributes to $20 \%$ of all maternal deaths. ${ }^{3}$ India alone contributes to about 80 per cent of the maternal deaths due to anaemia in South Asian region. ${ }^{4}$ Prevalence of anaemia among pregnant women in India is estimated to be $58.7 \%$, according to NFHS- 3 of 200506. ${ }^{5}$ DLHS 4 data stated that $53.2 \%$ of the pregnant women in the age group of 15-49 years in Puducherry had anaemia, while $2.8 \%$ of them were found to have severe anaemia. $^{6}$ IEC (Information, Education, and Communication) strategies may help pregnant women to prevent disease and to improve and maintain health. In particular, it may improve the wellbeing of the pregnant woman and the unborn baby through knowledge acquisition. It is suggested that interventions should also present satisfactory evidence with regards to the links between psychosocial or behavioral change and actual health impact..$^{7-9}$ The present study was carried out with an aim to evaluate the effectiveness of IEC in improving the knowledge and practice regarding prevention of iron deficiency anaemia among the antenatal women attending Primary Health Centre in Puducherry.

\section{METHODS}

The present study was carried out in Puducherry, a Union territory in South India, as a Randomised control trial among antenatal mothers attending antenatal clinics in Primary Health Centre from February 2016 to August 2017. Block randomization technique was used to designate study participants into intervention and nonintervention groups. The required sample size was calculated to be 84 in each group (Total - 168) which was estimated by using statistical formula for comparing two independent means. Those antenatal women who are health care workers and women with period of gestation more than 32 weeks were excluded from the study. After taking informed consent, knowledge and practice were assessed by predesigned questionnaire, which included questions on knowledge regarding causes, symptoms, diet, consequences in mother and fetus, prevention, treatment and practices regarding prevention/treatment of iron deficiency anaemia. All the questions were explained to the antenatal women and they were asked to fill it carefully. Then intervention (information, education and communication) was given to these antenatal women by using interpersonal communication methods, PowerPoint presentation and audio visual aids. The session lasted for 30-40 minutes duration. This exclusive programme was conducted till the target of 84 antenatal women was achieved. Haemoglobin levels of these antenatal women were also estimated. After a minimum period of two months, knowledge and practice was reassessed by using the same predesigned questionnaire and haemoglobin levels are estimated in both intervention and non intervention groups. Means and proportions were calculated for continuous and categorical variables respectively. McNemar test was applied to test for statistically significant difference in proportions before and after the intervention. Similarly, paired t test was applied to test statistical significance in difference between means before and after the interventions. Chi square test was applied to test for statistical difference in proportions. Institute ethical committee clearance certification was sought and obtained before the study was begun.

\section{RESULTS}

Among the 168 participants $77.4 \%$ were in the age group of $21-25$ years, $11.3 \%$ in the age group 26-30 years, and $10.1 \%$ in the age group $18-20$ years while only $1.2 \%$ of study participants were above 30 years of age. $56 \%$ were primigravida $44 \%$ were multigravida. Most of the participants $(75 \%)$ were lower middle class based on modified Kuppuswamy classification. $7.7 \%$ of participants were graduates, $52.4 \%$ had studied up to high school, whereas $5.4 \%$ were illiterate. Majority of the participants (94\%) belonged to Hindu religion. $79.2 \%$ of participants were from nuclear family and $20.8 \%$ were from joint family. $94 \%$ of them were taking mixed diet and $6 \%$ were vegetarian (Table 1).

Higher proportion of educated participants had a better pre-test knowledge score as compared to those who are less educated $(76.9 \%$ of graduates and above had good score against $12.5 \%$ of the participants with education of primary and middle school, $\mathrm{p}$ value $<0.001$ ) (Table 2). Higher proportion of participants in higher socio economic classes had a better pretest score as compared to those who belong to lower socio economic classes ( $p$ value $<0.001$ ) (Table 3 )

After intervention with IEC regarding the fact that anaemia is decreased level of haemoglobin, no statistically significant difference was observed in pre and post test among participants in both the study groups. ( $p$ value 0.25 vs. 0.125 ). For the question regarding iron intake and anaemia, the number of participants who gave correct response improved from $64.3 \%$ to $97.6 \%$ after intervention ( $\mathrm{p}$ value $<0.001$ ) which is statistically significant.

$92.8 \%$ of the participants in the interventional and non interventional group knew fatigue is a symptom of anaemia. By evaluating the post test results, it was found that there is no statistically significant difference observed among participants in both the study groups.(p value 0.063 vs. 1.0) For other questions regarding symptoms of anaemia, statistically significant difference was observed pre-test and post-test among participants in interventional group, however not in the non interventional group. Statistically significant difference was observed pre-test and post-test among patients in interventional group, however not in the non interventional group on knowledge regarding iron rich diet ( $\mathrm{p}$ value $<0.001$ ). 
Table 1: Comparison of study groups based on sociodemographic characteristics.

\begin{tabular}{|c|c|c|c|c|}
\hline \multirow[b]{2}{*}{$\begin{array}{l}\text { Sociodemographic } \\
\text { characteristics }\end{array}$} & \multicolumn{2}{|l|}{ Study group } & \multirow[b]{2}{*}{$\begin{array}{l}\text { Total } \\
\text { n }(\%)\end{array}$} & \multirow[b]{2}{*}{ p value* } \\
\hline & $\begin{array}{l}\text { Intervention group } n \\
(\%)\end{array}$ & $\begin{array}{l}\text { Non interventional group } n \\
(\%)\end{array}$ & & \\
\hline \multicolumn{5}{|l|}{ Age (in years) } \\
\hline $18-20$ & $8(9.5)$ & $9(10.7)$ & $17(10.1)$ & \multirow{4}{*}{0.302} \\
\hline $21-25$ & $62(73.8)$ & $68(81.0)$ & $130(77.4)$ & \\
\hline $26-30$ & $12(14.3)$ & $7(8.3)$ & $19(11.3)$ & \\
\hline$>30$ & $2(2.4)$ & $0(0.0)$ & $2(1.2)$ & \\
\hline \multicolumn{5}{|l|}{ Parity } \\
\hline Primi & $49(58.3)$ & $45(53.6)$ & $94(56.0)$ & \multirow{2}{*}{0.534} \\
\hline Multi & $35(41.7)$ & $39(46.4)$ & $74(44)$ & \\
\hline \multicolumn{5}{|l|}{ Socio economic class } \\
\hline Lower & $3(3.6)$ & $4(4.8)$ & $7(4.2)$ & \multirow{5}{*}{0.917} \\
\hline Upper lower & $4(4.8)$ & $6(7.1)$ & $10(6.0)$ & \\
\hline Lower middle & $63(75.0)$ & $63(75.0)$ & $126(75.0)$ & \\
\hline Upper middle & $7(8.3)$ & $6(7.1)$ & $13(7.7)$ & \\
\hline Upper & $7(8.3)$ & $5(6.0)$ & $13(7.7)$ & \\
\hline \multicolumn{5}{|l|}{ Educational status } \\
\hline Illiterate & $5(6.0)$ & $4(4.8)$ & $9(5.4)$ & \multirow{5}{*}{0.406} \\
\hline Primary and middle school & $8(9.5)$ & $16(19.0)$ & $24(14.3)$ & \\
\hline High school & $47(56.0)$ & $41(48.8)$ & $88(52.4)$ & \\
\hline Higher secondary school & $16(19.0)$ & $18(21.4)$ & $34(20.2)$ & \\
\hline Graduate & $8(9.5)$ & $5(6.0)$ & $13(7.7)$ & \\
\hline \multicolumn{5}{|l|}{ Religion } \\
\hline Hindu & $81(96.4)$ & $79(94.0)$ & $160(95.2)$ & \multirow{3}{*}{0.599} \\
\hline Christian & $2(2.4)$ & $2(2.4)$ & $4(2.4)$ & \\
\hline Muslim & $1(1.2)$ & $3(3.6)$ & $4(2.4)$ & \\
\hline \multicolumn{5}{|l|}{ Type of diet } \\
\hline Mixed & $80(95.2)$ & $78(92.9)$ & $158(94.0)$ & \multirow{2}{*}{0.514} \\
\hline Vegetarian & $4(4.8)$ & $6(7.1)$ & $10(6.0)$ & \\
\hline
\end{tabular}

* Chi square test was applied to test for statistical difference in proportions

Table 2: Comparison of study groups based on Pre and post-test responses to various questions.

\begin{tabular}{|c|c|c|c|c|c|c|}
\hline \multirow{2}{*}{$\begin{array}{l}\text { Questions } \\
\text { Pre-test } \\
\text { Post-test }\end{array}$} & \multirow[b]{2}{*}{$\begin{array}{l}\text { Study } \\
\text { group }\end{array}$} & \multicolumn{5}{|c|}{ Type of response } \\
\hline & & $\begin{array}{l}\text { Incorrect } \\
\text { Correct }\end{array}$ & Correct & Incorrect & $\begin{array}{l}\text { Correct } \\
\text { Incorrect }\end{array}$ & $\begin{array}{l}\text { p } \\
\text { value* }\end{array}$ \\
\hline \multirow{2}{*}{ Anaemia is decreased level of haemoglobin } & IG & $3(3.6)$ & $79(94.0)$ & $2(2.4)$ & $0(0.0)$ & 0.250 \\
\hline & NIG & $4(4.8)$ & $78(92.9)$ & $2(2.4)$ & $0(0.0)$ & 0.125 \\
\hline \multirow{2}{*}{ Anaemia in pregnancy is nutritional } & IG & $19(22.6)$ & $62(73.8)$ & $3(3.6)$ & $0(0.0)$ & $<0.001$ \\
\hline & NIG & $24(28.6)$ & $47(56.0)$ & $11(13.1)$ & $2(2.4)$ & $<0.001$ \\
\hline \multirow{2}{*}{ Iron intake can cause anaemia } & IG & $28(33.3)$ & $54(64.3)$ & $2(2.4)$ & $0(0.0)$ & $<0.001$ \\
\hline & NIG & $6(7.1)$ & $52(61.9)$ & $26(31.0)$ & $0(0.0)$ & 0.031 \\
\hline \multirow{2}{*}{ Hook worm infection can cause anaemia } & IG & $36(42.9)$ & $23(27.4)$ & $25(29.8)$ & $0(0.0)$ & $<0.001$ \\
\hline & NIG & $36(42.9)$ & $16(19.0)$ & $32(38.1)$ & $0(0.0)$ & $<0.001$ \\
\hline \multirow{2}{*}{$\begin{array}{l}\text { Repeated pregnancy with inadequate Spacing } \\
\text { can cause anaemia }\end{array}$} & IG & $6(7.1)$ & $71(84.5)$ & $4(4.8)$ & $3(3.6)$ & 0.508 \\
\hline & NIG & $6(7.1)$ & $62(73.8)$ & $16(19.0)$ & $0(0.0)$ & 0.031 \\
\hline \multirow{2}{*}{ Fatigue as symptom of IDA } & IG & $5(6.0)$ & $78(92.9)$ & $1(1.2)$ & $0(0.0)$ & 0.063 \\
\hline & NIG & $0(0.0)$ & $78(92.9)$ & $6(7.1)$ & $0(0.0)$ & 1.0 \\
\hline \multirow{2}{*}{ Loss of appetite as symptom of IDA } & IG & $16(19.0)$ & $64(76.2)$ & $4(4.8)$ & $0(0.0)$ & $<0.001$ \\
\hline & NIG & $0(0.0)$ & $59(70.2)$ & $25(29.8)$ & $0(0.0)$ & 1.0 \\
\hline \multirow{2}{*}{ Breathlessness as symptom of IDA } & IG & $27(32.1)$ & $54(64.3)$ & $3(3.6)$ & $0(0.0)$ & $<0.001$ \\
\hline & NIG & $3(3.6)$ & $53(63.1)$ & $28(33.3)$ & $0(0.0)$ & 0.250 \\
\hline
\end{tabular}




\begin{tabular}{|c|c|c|c|c|c|c|}
\hline \multirow{2}{*}{$\begin{array}{l}\text { Questions } \\
\text { Pre-test } \\
\text { Post-test }\end{array}$} & \multirow[b]{2}{*}{$\begin{array}{l}\text { Study } \\
\text { group }\end{array}$} & \multicolumn{5}{|c|}{ Type of response } \\
\hline & & $\begin{array}{l}\text { Incorrect } \\
\text { Correct }\end{array}$ & $\begin{array}{l}\text { Correct } \\
\text { Correct }\end{array}$ & $\begin{array}{l}\text { Incorrect } \\
\text { Incorrect }\end{array}$ & $\begin{array}{l}\text { Correct } \\
\text { Incorrect }\end{array}$ & p value* \\
\hline \multirow{2}{*}{ Palpitation as symptom of IDA } & IG & $17(20.2)$ & $60(71.4)$ & $7(8.3)$ & $0(0.0)$ & $<0.001$ \\
\hline & NIG & $4(4.8)$ & $58(69.0)$ & $21(25.0)$ & $1(1.2)$ & 0.375 \\
\hline \multirow{2}{*}{ GLV are poor source of iron } & IG & $6(7.1)$ & $75(89.3)$ & $1(1.2)$ & $2(2.4)$ & 0.289 \\
\hline & NIG & $0(0.0)$ & $76(90.5)$ & $7(8.3)$ & $1(1.2)$ & 1.0 \\
\hline \multirow{2}{*}{ Meat and Egg contain iron } & IG & $39(46.4)$ & $43(51.2)$ & $2(2.4)$ & $0(0.0)$ & $<0.001$ \\
\hline & NIG & $1(1.2)$ & $55(65.5)$ & $28(33.3)$ & $0(0.0)$ & 1.0 \\
\hline \multirow{2}{*}{$\begin{array}{l}\text { Meat and egg has readily available iron than } \\
\text { GLV }\end{array}$} & IG & $64(76.2)$ & $13(15.5)$ & $7(8.3)$ & $0(0.0)$ & $<0.001$ \\
\hline & NIG & $1(1.2)$ & $9(10.7)$ & $74(88.1)$ & $0(0.0)$ & 1.0 \\
\hline \multirow{2}{*}{ Lemon decreases iron absorption } & IG & $74(88.1)$ & $6(7.1)$ & $4(4.8)$ & $0(0.0)$ & $<0.001$ \\
\hline & $\mathrm{NIG}$ & $0(0.0)$ & $4(4.8)$ & $79(94.0)$ & $1(1.2)$ & 1.0 \\
\hline \multirow{2}{*}{ Jaggery is rich source of iron } & IG & $18(21.4)$ & $63(75.0)$ & $3(3.6)$ & $0(0.0)$ & $<0.001$ \\
\hline & NIG & $2(2.4)$ & $60(71.4)$ & $22(26.2)$ & $0(0.0)$ & 0.5 \\
\hline \multirow{2}{*}{ Absorption of iron is increased by tea } & IG & $73(86.9)$ & $6(7.1)$ & $5(6.0)$ & $0(0.0)$ & $<0.001$ \\
\hline & NIG & $0(0.0)$ & $5(6.0)$ & $79(94.0)$ & $0(0.0)$ & 1.0 \\
\hline \multirow{2}{*}{ Iron deficiency can lead to infection in mother } & IG & $15(17.9)$ & $66(78.6)$ & $3(3.6)$ & $0(0.0)$ & $<0.001$ \\
\hline & NIG & $0(0.0)$ & $69(82.1)$ & $15(17.9)$ & $0(0.0)$ & 1.0 \\
\hline \multirow{2}{*}{ Iron deficiency can lead to preterm labour } & IG & $21(25.0)$ & $57(67.9)$ & $6(7.1)$ & $0(0.0)$ & $<0.001$ \\
\hline & NIG & $10(11.1)$ & $53(63.1)$ & $21(25)$ & $0(0.0)$ & 0.002 \\
\hline \multirow{2}{*}{$\begin{array}{l}\text { Iron deficiency can lead to inability to } \\
\text { withstand PPH }\end{array}$} & IG & $28(33.3)$ & $54(64.3)$ & $2(2.4)$ & $0(0.0)$ & $<0.001$ \\
\hline & NIG & $2(2.4)$ & $67(79.8)$ & $14(16.7)$ & $1(1.2)$ & 1.0 \\
\hline \multirow{2}{*}{ Iron deficiency can lead to puerperal sepsis } & IG & $14(16.7)$ & $67(79.8)$ & $3(3.6)$ & $0(0.0)$ & $<0.001$ \\
\hline & NIG & $0(0.0)$ & $66(78.6)$ & $18(21.4)$ & $0(0.0)$ & 1.0 \\
\hline \multirow{2}{*}{ Iron deficiency can lead to IUGR } & IG & $9(10.7)$ & $70(83.3)$ & $5(6.0)$ & $0(0.0)$ & 0.004 \\
\hline & NIG & $2(2.4)$ & $59(70.2)$ & $12(14.3)$ & $11(13.1)$ & 0.022 \\
\hline \multirow{2}{*}{$\begin{array}{l}\text { Iron deficiency can lead to increased risk of } \\
\text { premature baby }\end{array}$} & IG & $27(32.1)$ & $52(61.9)$ & $5(6.0)$ & $0(0.0)$ & $<0.001$ \\
\hline & NIG & $1(1.2)$ & $52(61.9)$ & $27(32.1)$ & $4(4.8)$ & 0.375 \\
\hline \multirow{2}{*}{$\begin{array}{l}\text { Iron deficiency can impair intelligence of } \\
\text { baby }\end{array}$} & IG & $16(19.0)$ & $64(76.2)$ & $4(4.8)$ & $0(0.0)$ & $<0.001$ \\
\hline & $\mathrm{NIG}$ & $2(2.4)$ & $66(78.6)$ & $16(19.0)$ & $0(0.0)$ & 0.5 \\
\hline \multirow{2}{*}{$\begin{array}{l}\text { Iron deficiency can impair health and growth } \\
\text { of baby in future }\end{array}$} & IG & $23(27.4)$ & $58(69.0)$ & $3(3.6)$ & $0(0.0)$ & $<0.001$ \\
\hline & NIG & $1(1.2)$ & $66(78.6)$ & $17(20.2)$ & $0(0.0)$ & 1.0 \\
\hline \multirow{2}{*}{ Iron rich food is necessary in pregnancy } & IG & $18(21.4)$ & $61(72.6)$ & $4(4.8)$ & $1(1.2)$ & $<0.001$ \\
\hline & NIG & $1(1.2)$ & $71(84.5)$ & $12(14.3)$ & $0(0.0)$ & 1.0 \\
\hline \multirow{2}{*}{ Knowledge on free supply of iron tablets } & IG & $5(6.0)$ & 77 (91.7) & $2(2.4)$ & $0(0.0)$ & 0.063 \\
\hline & NIG & $1(1.2)$ & $74(88.1)$ & $9(10.7)$ & $0(0.0)$ & 1.0 \\
\hline \multirow{2}{*}{$\begin{array}{l}\text { Knowledge on availability of treatment for } \\
\text { hookworm infestation }\end{array}$} & IG & $67(79.8)$ & $12(14.3)$ & $5(6.0)$ & $0(0.0)$ & $<0.001$ \\
\hline & $\mathrm{NIG}$ & $0(0.0)$ & $7(8.3)$ & 77 (91.7) & $0(0.0)$ & 1.0 \\
\hline
\end{tabular}

*McNemar test was applied to test statistical difference in proportions; IG - Intervention Group and NIG - Non Intervention Group.

Table 3: Comparison of study groups based on intervention responses.

\begin{tabular}{|c|c|c|c|c|c|c|}
\hline \multirow{2}{*}{$\begin{array}{l}\text { Questions } \\
\text { Pre test } \\
\text { Post test }\end{array}$} & \multirow[b]{2}{*}{$\begin{array}{l}\text { Study } \\
\text { group }\end{array}$} & \multicolumn{5}{|c|}{ Type of response } \\
\hline & & $\begin{array}{l}\text { No } \\
\text { Yes }\end{array}$ & $\begin{array}{l}\text { Yes } \\
\text { Yes }\end{array}$ & $\begin{array}{l}\text { No } \\
\text { No }\end{array}$ & $\begin{array}{l}\text { Yes } \\
\text { No }\end{array}$ & p value* \\
\hline \multirow{2}{*}{ Compliance to IFA tablets } & IG & $7(8.3)$ & $75(89.3)$ & $2(2.4)$ & $0(0.0)$ & 0.016 \\
\hline & NIG & $2(2.4)$ & $77(91.7)$ & $5(6.0)$ & $0(0.0)$ & 0.5 \\
\hline \multirow{2}{*}{ Regular GLV in diet } & IG & $17(20.2)$ & $64(76.2)$ & $3(3.6)$ & $0(0.0)$ & $<0.001$ \\
\hline & NIG & $0(0.0)$ & $72(85.7)$ & $12(14.3)$ & $0(0.0)$ & 1.0 \\
\hline \multirow{2}{*}{ Compliance to Vitamin $\mathrm{C}$ tablets } & IG & $31(36.9)$ & $1(1.2)$ & $51(60.7)$ & $1(1.2)$ & $<0.001$ \\
\hline & NIG & $0(0.0)$ & $12(14.3)$ & $72(85.7)$ & $0(0.0)$ & 1.0 \\
\hline
\end{tabular}

*McNemar test was applied to test statistical difference in proportions; IG - Intervention Group, NIG - Non Intervention Group, IFA - Iron and Folic Acid, GLV - Green Leafy Vegetables. 
Table 4: Hb values of study groups before and after intervention.

\begin{tabular}{|llllll|}
\hline Mean Hb (in gm/dL) & $\begin{array}{l}\text { Study group } \\
\text { Intervention } \\
\text { group }\end{array}$ & $\begin{array}{l}\text { Non interventional } \\
\text { group }\end{array}$ & $\begin{array}{l}\text { Difference } \\
\text { in mean }\end{array}$ & $\begin{array}{l}95 \% \text { CI of } \\
\text { difference in means }\end{array}$ & $\begin{array}{l}\text { p } \\
\text { value* }\end{array}$ \\
\hline Pre intervention/ follow up & $9.72 \pm 0.88$ & $9.7 \pm 0.57$ & 0.52 & $0.43-0.62$ & $<0.001$ \\
\hline Post test intervention/follow up & $10.25 \pm 0.92$ & $9.9 \pm 0.6$ & 0.21 & $0.13-0.29$ & $<0.001$ \\
\hline
\end{tabular}

On knowledge regarding consequences in fetus, statistically significant difference was observed pre-test and post-test among participants in interventional groups, however not in non interventional group ( $p$ value $<0.001)$.

After the intervention the knowledge on iron supplements improved to $94 \%$ in the interventional groups which is statistically significant ( $\mathrm{p}$ value 0.001 in interventions vs. 1.0 in non interventional groups).

Before intervention $91.6 \%$ participants in the intervention group and $88 \%$ of participants in the non interventional group knew about the free supply of iron folic acid tablets and after intervention statistically significant difference was observed pre-test and post-test among the participants in the interventional group, however not in the non interventional group ( $p$ value 0.063 in interventional vs. 1.0 in non interventional groups).

On comparison of overall post-test score for correct response of the study participants in between the two groups, higher score was seen in the interventional group and this difference was found to be statistically significant ( $\mathrm{p}$ value $<0.001$ ).

Statistically significant difference was observed in the pre-test and post-test haemoglobin values among participants in both the groups. However, the magnitude of difference was found to be high in the interventional group as compared to that of the non-interventional group ( $\mathrm{p}$ value $<0.001$ )

\section{DISCUSSION}

Majority of the study participants were in the age group of $21-25$ years $(77.4 \%)$, primi $(56.0 \%)$, belonged to lower middle class $(75.0 \%)$, educated up to high school (52.0\%) and followed Hindu religion $(94.0 \%)$. Higher proportion of educated participants had a better pre-test knowledge score as compared to those who are less educated $(76.9 \%$ of Graduates and above had good score against $12.5 \%$ of participants with education of primary and middle school, $\mathrm{p}$ value $<0.001$ ) and higher proportion of participants in higher socio economic class had a better pre-test knowledge score as compared to those who are in lower socio economic classes $(83.3 \%$ of the participants in upper class good score vs. $50 \%$ in lower middle class and $0 \%$ among participants in lower class, $\mathrm{p}$ value <0.001) In the present study overall pretest score of the study participants ranged from fair (11-20) to good (21-30) in $49.4 \%$ and $46.4 \%$ of them respectively. Baby $\mathrm{A}$ et al, in their research work conducted in Karnataka observed that the majority of the antenatal mothers (54\%) had satisfactory knowledge, $38 \%$ had poor knowledge, and $8 \%$ had good knowledge regarding anemia during pregnancy. ${ }^{10}$ These observations were in agreement with the results of the present study.

A cross sectional study was undertaken by Nivedita $\mathrm{K}$ et al, in Puducherry, which reported that assessment of knowledge revealed that only $39.87 \%$ of the participants were aware of and understood the term anaemia. ${ }^{11}$ Balasubramanian $\mathrm{T}$ et al, in their study observed that $76.5 \%$ are aware of anemia. ${ }^{12}$ Mohannad A et al, reported that most of the respondents $(66 \%)$ had heard about anemia as a health problem and $42 \%$ could not identify any of the causes. ${ }^{13}$ However in the present study $>70 \%$ of the study participants gave a correct response for similar questions.

Nearly $53.8 \%$ of the participants accepted that pregnant women were more vulnerable to anemia and $66.1 \%$ responded correctly that the fetus will be affected by severe anemia in the study by Nivedita $\mathrm{K}$ et al, while in the present study a higher proportion of $80.9 \%$ of the women gave a correct response for the similar question. ${ }^{11}$ Balasubramanian $\mathrm{T}$ et al in their study noted that $47 \%$ knows anemia is more common in pregnant women. ${ }^{12}$ In Nivedita $\mathrm{K}$ et al, study only $32.6 \%$ gave the correct response that pregnant women should take iron supplementation in spite of taking a healthy diet. ${ }^{11}$ Only $44.62 \%$ of the participants were aware of their hemoglobin level in the current pregnancy. Knowledge about food rich in iron was poor among the participants. In the present study pre intervention compliance to IFA tablets was $>90 \%$ among all the study participants and knowledge about iron rich food items was found to be fairly adequate. A similar proportion of compliance to IFA tablets $(90 \%)$ was observed by Kulkarni KK et al. ${ }^{14}$ It was reported in the same study that nearly $50 \%$ of their study participants were correctly aware of the iron rich foods. Overall knowledge regarding iron rich foods was reported to be low in Mohannad A et al, study. ${ }^{13}$

George $\mathrm{M}$ et al, reported that among their study participants, most of them $82.67 \%$ had good knowledge regarding anemia. ${ }^{15}$ This observation was comparable to that of the present study results. It was found that pregnant women were not sure about the motive of IFA 
tablets given to them, in the study by Bhardhwaj AK et al. ${ }^{16}$ Similar observations were noted in the present study also.

Mohannad A et al, in their research work stated that more than half $(51 \%)$ of the respondents had no knowledge about the positive effect of vitamin $\mathrm{C}$ on iron absorption. ${ }^{13}$ Consumption of green leafy vegetables was low and only $56 \%$ of them were taking iron supplements regularly. Nearly $53 \%$ of the study participants responded correctly for the questions related to green leafy vegetables and a similar proportion responded correctly for the questions related to vitamin $\mathrm{C}$ in the present study, which was comparable to the above discussed study.

Yadav RK et al, reported in the study that none of the illiterate women gave any correct answer regarding sign and symptoms of anemia. ${ }^{17}$ Majority of correct answers regarding sign and symptoms of anemia was given by women who were graduates. The study found that there was significant association between sign and symptoms of anemia and women's education. This finding was similar to the observation of the present study showed where higher proportion of educated participants had a better pre test knowledge score as compared to those who are less educated.

After the intervention, in the present study magnitude of difference in the haemoglobin values was found to be high in the intervention group compared to non intervention group. (p value $<0.001$ ). Similarly, Shivalli S et al, observed that the magnitude of improvement in mean haemoglobin levels in the interventional group was more when compared to control group. ${ }^{18}$

Some of the possible limitations of the present study are because of wide geographic, cultural and linguistic variations the intervention used in the present study may not prove useful in other parts of the country. However, the study demonstrated improving the knowledge of the mothers on anaemia improves their haemoglobin levels and the questions used to assess the knowledge were limited, though the same set of questions were used in both pre-test and post-test.

\section{CONCLUSION}

The level knowledge on anaemia among the antenatal mothers attending a tertiary care government health facility was found to range from good to excellent in majority. Well planned and tailor made IEC material, to be acceptable by the regional population, by using various modes of interpersonal communications improves the knowledge of the antenatal mothers. It was also found that the haemoglobin levels of mothers in intervention group had a larger increase as compared to the antenatal mothers who did not receive any IEC intervention.

Though the increase in haemoglobin levels are relatively less, on considering the population as whole, this may have a larger impact in decreasing the prevalence of anaemia in antenatal mothers including their subsequent pregnancies and their children.

\section{ACKNOWLEDGMENTS}

Authors would like to thank to Dr. M. Subashini, and guide for her invaluable guidance, constant encouragement, immense patience, support and interest which she has generously shown during the preparation of this dissertation. We express our gratitude and thanks to Dr. Nina V. Kate., our co-guide for her extra-ordinary and constant support and we are very grateful to Dr. P. Sujatha, Medical Superintendent RGGW and $\mathrm{CH}$ Pondicherry for arranging, allowing and rendering necessary help.

We express our gratitude and thanks to Dr. Vishnuprasad statistician for his guidance and encouragement which helped us in completing our thesis. Our acknowledgements are also for the medical officers, nurses and technicians in RGGW and $\mathrm{CH}$ Pondicherry, and thank all our colleagues, parents and our teachers for their encouragement and co-operation throughout our study. We extend my heartfelt thanks to all patients who participants in the study for their co-operation.

Funding: No funding sources

Conflict of interest: None declared

Ethical approval: The study was approved by the Institutional Ethics Committee

\section{REFERENCES}

1. Stoltzfus RJ, Dreyfuss ML, Organization WH. Guidelines for the use of iron supplements to prevent and treat iron deficiency anemia: Ilsi Press Washington eDC DC; 1998.

2. Organization WH. Iron deficiency anaemia: assessment, prevention and control: a guide for programme managers. 2001.

3. Micronutrient Deficiencies. Available at: http://www.who.int/nutrition/topics/ida/en/. Accessed on 25 May 2016.

4. Ezzati M, Lopez AD, Rodgers A, Vander Hoorn S, Murray CJ. Selected major risk factors and global and regional burden of disease. Lancet. 2002;360:1347-60.

5. National Family Health Survey (NFHS-3). Mumbai, 2007. Available at: http://rchiips.org/nfhs/NFHS3\%20Data/VOL-1/India_volume_I__corrected_17 oct08.pdf. Accessed on 25 May 2017.

6. State Fact Sheet- Puducherry. 2012-13. Available at: http://rchiips.org/pdf/dlhs4/report/PU.pdf. Accessed 25 May 2017.

7. Curtis V, Kanki B, Cousens S, Diallo I, Kpozehouen A, Sangare M. Evidence of behaviour change following a hygiene promotion programme in Burkina Faso. Bulletin of the World Health Organization. 2001;79:518-27. 
8. Glasgow RE, Klesges LM, Dzewaltowski DA, Bull SS, Estabrooks P. The future of health behavior change research: what is needed to improve translation of research into health promotion practice?. An Behavioral Med. 2004;27:3.

9. Panter-Brick C, Clarke SE, Lomas H, Pinder M, Lindsay SW. Culturally compelling strategies for behaviour change: a social ecology model and case study in malaria prevention. Social Science Med. 2006;62:2810-25.

10. Baby A, Venugopal J, D'silva R, Chacko S, Vineesha $\mathrm{P}$, Kumary TV. Knowledge on management of anemia during pregnancy: a descriptive study. Arch Med Health Sci. 2014;2:140.

11. Nivedita K. Knowledge, attitude and practices of pregnant women regarding anemia, iron rich diet and iron supplement. Int $\mathbf{J}$ Reprod Contra Obstet Gynecol. 2016;5:425-31.

12. Balasubramanian T, Aravazhi M, Sampath SD. Awareness of anemia among pregnant women and impact of demographic factors on their hemoglobin status. Int J Sci Stud. 2016;3:303-5.

13. Ayesha Mohannad FR, Irfan G. Impact of maternal education, and socioeconomic status on maternal nutritional knowledge and practices regarding iron rich foods and iron supplements. Ann Pak Inst Med Sci. 2012;8:101-5.

14. Kulkarni KK. KAP Studies among Indian antenatal women: can we reduce the incidence of anemia? J Obstet Gynaecol India. 2015;65:320-2.
15. George M, George N, Ramesh N. Awareness regarding anemia, gestational diabetes and pregnancy induced hypertension among antenatal women attending outpatient department in a rural hospital. Hindu. 2016;142:94-7.

16. Bhardwaj A, Ahluwalia S, Vaidya N. Preventing anaemia in pregnancy-need for intensive IEC activities. Indian J Com Health. 1995;8:31-3.

17. Yadav RK, Swamy M, Banjade B. Knowledge and practice of anemia among pregnant women attending antenatal clinic in Dr. Prabhakar Kore hospital, Karnataka-a cross sectional study. Literacy. 2014;30:18.

18. Shivalli S, Srivastava RK, Singh GP. Trials of improved practices (TIPs) to enhance the dietary anf iron-folate intake during pregnancy- a quasi experimental study among rural pregnant women of Varanasi, India. PLoS One. 2015;10(9):e0137735.

Cite this article as: Chandran A, Subashini M, Kate $\mathrm{N}$. The effect of information, education and communication on knowledge and practice regarding prevention/treatment of iron deficiency anaemia among the antenatal women attending primary health centre in Puducherry, India: a randomised control study. Int J Reprod Contracept Obstet Gynecol 2019;8:2315-21. 